\title{
A guideline for placement of an infra- acetabular screw based on anatomic landmarks via an intra-pelvic approach
}

\author{
Florian Baumann ${ }^{1 *}$ (D, Paul Schmitz ${ }^{1}$, Daniel Mahr ${ }^{1}$, Maximilian Kerschbaum ${ }^{1}$, Axel Gänsslen ${ }^{2}$, Michael Nerlich ${ }^{1}$ \\ and Michael Worlicek
}

\begin{abstract}
Background: Due to demographic changes, more and more fracture patterns involving anterior acetabular structures occur. The infra-acetabular screw is seen a useful tool to increase stability in fixation of the acetabular cup. However, the exact position of this screw in relation to anatomic landmarks which are intra-operatively palpable via an intra-pelvic approach has not yet been determined.
\end{abstract}

Methods: This biomorphometric experimental study references the ideal screw position of an infra-acetabular screw to anatomic landmarks palpable via an intra-pelvic approach. Therefore, we created a computer tomography-based 3D-model of 40 patients (20 women, 20 men) who received a computer tomography (CT) scan of the pelvis for any other reason than an acetabular fracture.

Results: The entry point of an ideal infra-acetabular was of high constancy. At mean, this point was $10.2 \mathrm{~mm}$ caudal and $10.4 \mathrm{~mm}$ medial of the ilio-pubic/ilio-pectineal eminence. This reference is independent of age, gender, or physical dimensions. However, we found gender-dependent differences for the angulation and the length of the screw.

Conclusions: This study provides a comprehensive guideline to determine the ideal entry point for an infra-acetabular screw via an intra-pelvic approach. The entry point is located $10.2 \mathrm{~mm}$ caudal and $10.4 \mathrm{~mm}$ medial of the ilio-pubic/ ilio-pectineal eminence.

Trial registration: Clinical Trial Registry University of Regensburg Z-2017-0930-1. Registered 04. Dec 2017.

Keywords: Acetabulum fracture, Screw fixation, Entry point, Infra-acetabular screw, Anatomic landmarks, Intra-pelvic approach

\section{Background}

Treatment of fractures of the acetabulum is one of the most challenging procedures in trauma surgery. Achieving an anatomic reduction of the joint surface can be demanding. However, it is necessary to establish a rigid fixation to retain the position until the fracture has healed.

Large register studies on the epidemiology of acetabular fractures have shown an increasing number of cases with involvement of the anterior acetabular column during the last 20 years [19]. Therefore, anterior approaches and anterior operating techniques have been advanced

\footnotetext{
* Correspondence: florian.baumann@ukr.de

'Department of Trauma Surgery, Regensburg University Medical Center,

93042 Regensburg, Germany

Full list of author information is available at the end of the article
}

$[2,3,8,10,12,17]$. A dissociation of the anterior column to the posterior column or dislocation of the quadrilateral surface has been identified as a risk factor for a secondary dislocation leading to a central subluxation of the femoral head [3, 23, 24]. Several concepts to support the medial acetabular border have been introduced $[4,5,11,14,18,21,24]$. The infra-acetabular screw following Letournel's $[16,17]$ concept of a periacetabular frame was described in 2011 by Culemann et al. [5]. Culemann et al. determined the entry point $1 \mathrm{~cm}$ caudal to the ilio-pubic/ilio-pectineal eminence (IPE) in the middle of the pubic ramus and stated that this screw was only applicable through an ilio-inguinal 
approach [5]. However, the intra-pelvic approach has become the working horse for acetabulum fractures today $[2,12]$. Over the past years, experience and capabilities with this approach have been extended [7]. Hence, clinical experience has proven that the entry point and path of entry can easily be exposed. However, the exposure of the lateral border of the pubic rim is not as good as with the ilio-inguinal approach, and therefore, the instructions given by Culemann et al. for an ideal screw position (Fig. 1) are difficult to follow via an intra-pelvic approach $[1,5,13,17]$.

The purpose of the study is to specify the ideal position of the infra-acetabular screw in relation to anatomic landmarks that are accessible via an intra-pelvic approach.

\section{Methods}

The Ethics Committee at the University of Regensburg approved the study in January 2018 (Institutional Review Board Number 17-705649-180). The study is registered at the Clinical Trial Registry University of Regensburg Z-2017-0930-1. All procedures performed in studies were in accordance with the 1964 Helsinki declaration.

This study is an experimental computer tomographybased 3D-model analysis to reference the ideal screw position of an infra-acetabular screw to anatomic landmarks. We investigated 3D-computer tomography (CT) scans of 40 patients (20 women, 20 men) obtained by the Department of Radiology of our institution.

Baseline characteristics of the study group are shown in Table 1. CT measurements were carried out using the "semi-automatic" function of a digital 3D CT-based planning software (Modicas, Erlangen, Germany). This mode offers the possibility to assess the pelvis in three dimensions, to exactly determine the axes, and to automatically calculate angles and to measure distances. First, the pelvis was virtually aligned in order to bring the anterior pelvic plane (APP) in congruence with the coronal plane, to have a constant starting point. The APP was defined as the triangle between the pelvic symphysis and both spinae iliacae anteriores superiores. The pelvic inlet plane was identified by the angle point of the pelvic brim at level of the acetabulum on both sides and the cranial margin of the pubic symphysis.

The optimal position of the infra-acetabular screw was identified by locating the infra-acetabular corridor on axial views of the CT. The first point of the straight line through the infra-acetabular corridor was defined by the center of the acetabular fossa, $2 \mathrm{~mm}$ lateral to the quadrilateral surface. Then, the straight line was placed parallel to the quadrilateral surface and symmetrically along the infra-acetabular corridor into the ischial cortex. After determination of the optimal position of the screw, the orientation of the screw was defined by measuring the sagittal $(\alpha)$ and axial $(\beta)$ angles in relation to the pelvic inlet plane. The entry point of the straight line was referenced by measuring the relation to the apex of the IPE. Therefore, the distance was measured on a horizontal line $(x)$ and on a perpendicular $(y)$ line (Fig. 2).

\section{Statistical analysis}

Statistical analysis was performed using the software package SPSS (Version 23, SPSS Inc., Chicago, IL).

Since there is no previous data on the variance of the entry point, this preliminary study was designed as an exploratory pilot study without any a priori sample size calculation based on a primary endpoint. Based on the variance of the angle related to the anterior pelvic plane, a sample size of 40 patients was considered feasible and expected to have enough power.

For comparison of mean values, we used the independent $t$ test. The Spearmen's rank correlation was used to investigate a relationship between age, height, and weight of the patient. Correlation coefficients $\geq .40$ indicate a relevant relationship. Unless otherwise stated, descriptive data are given as mean \pm standard deviation. The level of significance was at $p<0.05$ for all tests.

\section{Results}

Table 1 shows baseline data recorded in 40 patients. The mean entry point for an ideal infra-acetabular screw was $10.2 \mathrm{~mm}( \pm 1.4)$ caudal and $10.4 \mathrm{~mm}( \pm 1.0)$ medial to the IPE. There was also no significant difference for the
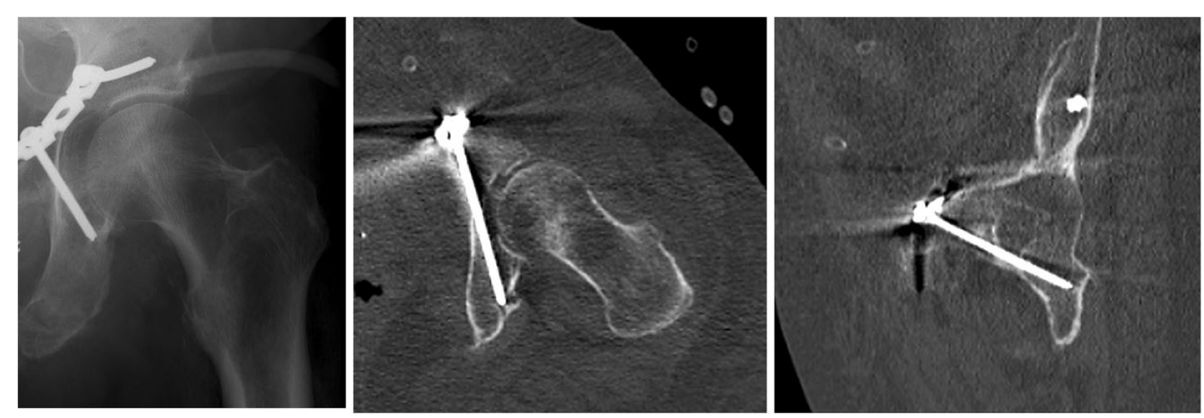

Fig. 1 Radiographs showing an ideal position of the infra-acetabular screw 
Table 1 Measurement results for the ideal position of an infra-acetabular screw

\begin{tabular}{lllll}
\hline$N=40$ & Female & Male & $\begin{array}{l}\text { Level of significance female } \\
\text { compared to male patients }\end{array}$ & Total \\
\hline Distance medial IPIS (in mm) & $10.6 \pm 1.22(8.5-14.1)$ & $10.2 \pm 0.73(8.6-12.0)$ & $p=0.770$ & $10.4 \pm 1.02(8.5-14.1)$ \\
Distance caudal IPIS (in mm) & $10.2 \pm 1.61(3.0-13.2)$ & $10.2 \pm 1.07(8.4-13.7)$ & $p=0.883$ & $10.2 \pm 1.36(3.0-13.70)$ \\
Sagittal angle (a) to PIP (in degrees) & $9.6 \pm 1.16(6.9-12.4)$ & $11.2 \pm 1.57(8.8-15.1)$ & $p=0.000$ & $10.4 \pm 1.58(6.9-15.10)$ \\
Axial angle ( $\beta$ ) to PIP (in degrees) & $71.4 \pm 3.55(66.7-89.4)$ & $69.5 \pm 2.42(62.3-74.3)$ & $p=0.006$ & $70.5 \pm 3.17(62.3-89.4)$ \\
Screw length (in mm) & $74.8 \pm 3.4(70.20-84.00)$ & $83.9 \pm 2.05(79.80-88.30)$ & $p=0.000$ & $79.3 \pm 5.37(70.2-88.30)$ \\
\hline
\end{tabular}

position of the entry point between male and female patients (Fig. 3a). The mean length of the infra-acetabular corridor was $79.2 \mathrm{~mm}( \pm 5.3)$ (Fig. 3b). We found a significant difference between male and female patients concerning the length of the corridor. The mean length in female patients was $74.8 \mathrm{~mm}( \pm 3.4)$ and in male patients, $83.9 \mathrm{~mm}( \pm 2.1)(p=0.000)$ respectively.

The mean angle of both left and right screw related to the axial plane was $10.4^{\circ}\left( \pm 1.6^{\circ}\right)$ and to the sagittal plane $70.5^{\circ}( \pm 3.2)$. The mean angle in female patients related to the axial plane was $11.2^{\circ}( \pm 1.6)$ and to the sagittal plane $71.4^{\circ}( \pm 3.6)$. Male patients had a mean angle of $9.6^{\circ}\left( \pm 1.2^{\circ}\right)$ related to the axial plane and $71.4^{\circ}( \pm 3.6)$ to the sagittal plane. This differences between female and male patients were significant $(p=0.006$ for the sagittal and $p=0.000$ for the axial plane). We did not find any significant difference between the right and left side concerning the screw position, length of the corridor, or angulation. Figure 4 shows 3D-CT virtual reality images illustrating the angle of the drill of the left and right screw by lines in relation to the proximal interphalangeal (PIP).

\section{Discussion}

The most important finding of the present study is that the ideal entry point for an infra-acetabular screw is $10.2 \mathrm{~mm}$ caudal and $10.4 \mathrm{~mm}$ medial of the IPE. This is the first study to report on the ideal screw position in relation to directly palpable landmarks via an intra-pelvic approach. Additionally, we referenced the angle of the screw to the pelvic inlet plane which is visible intraoperatively. This referencing in relation to visible anatomic landmarks may allow the surgeon to reproducibly place the infraacetabular screw in an optimal position.

Demographic changes lead to a rising number of geriatric acetabular fractures involving anterior acetabular structures (anterior wall/anterior column) [6, 19, 20, 23]. Baseline data of our patient population regarding age and physical dimensions reflect the characteristics of a typical patient population for fractures involving anterior acetabular elements. This is concordant with other studies on the configuration of the infra-acetabular corridor [5, 9].

Historically, the posterior Kocher/Langenbeck approach was the standard approach to stabilize acetabular

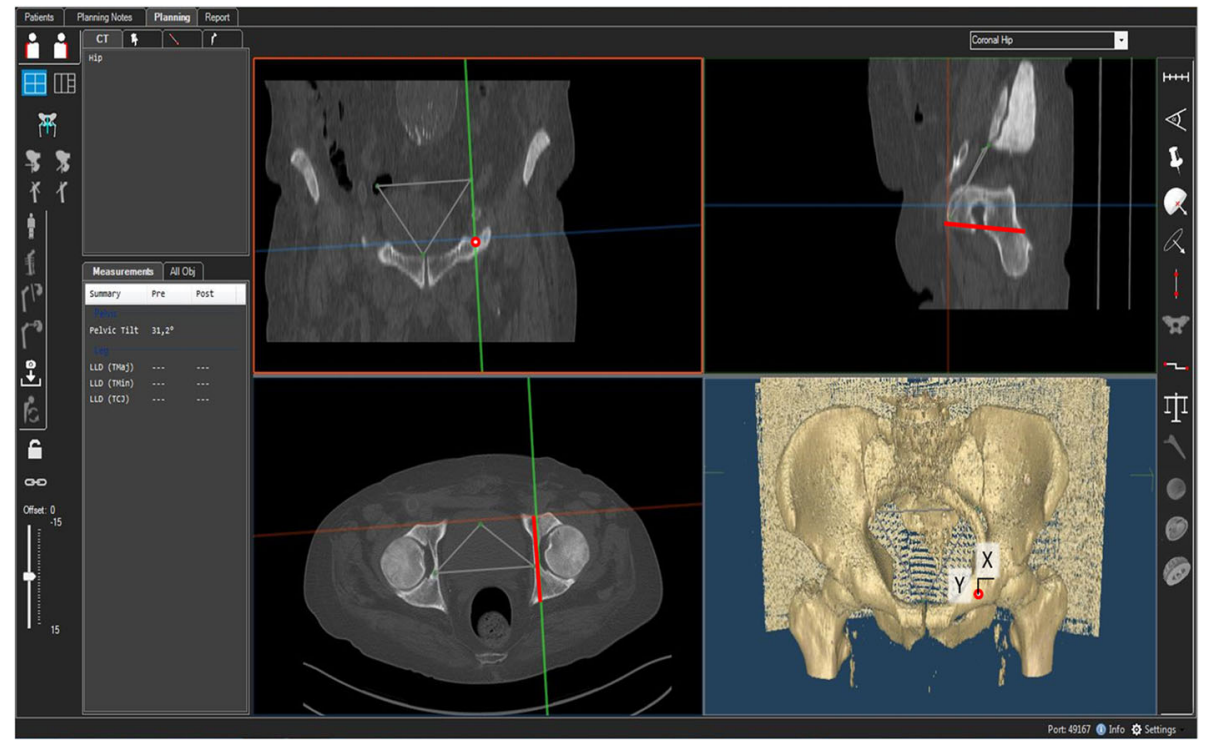

Fig. 2 Setting of the 3D-CT-based measurement of the infra-acetabular screw position 

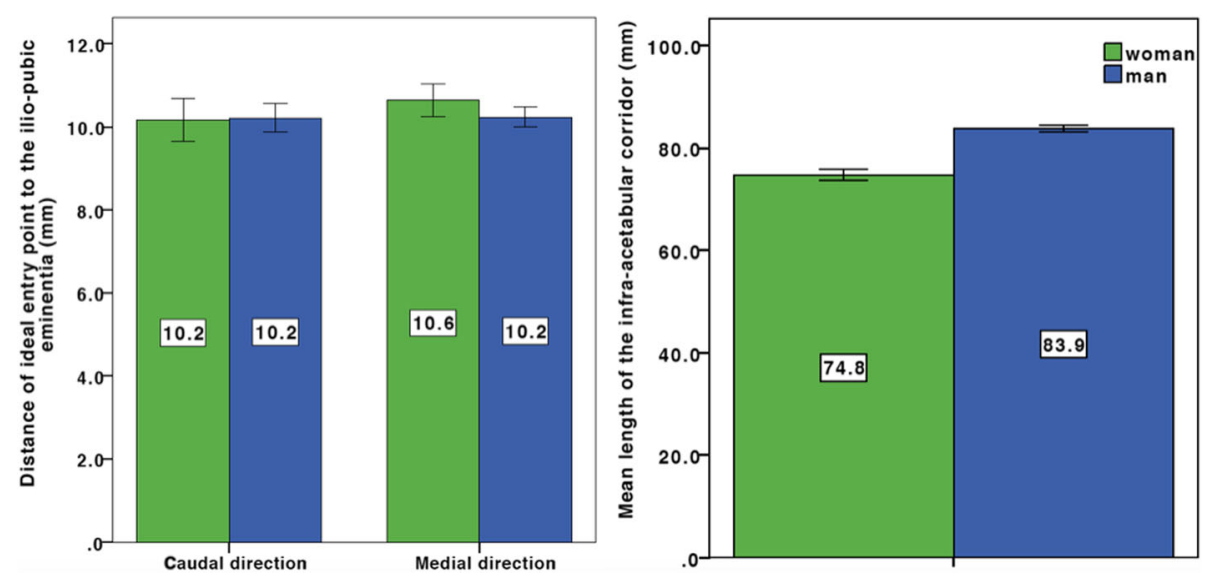

Fig. 3 Boxplot of the distance of the ideal entry point to the ilio-pubic/ilio-pectineal eminence and the screw length

fractures $[13,16]$. During the last 20 years, fracture patterns have changed so that anterior approaches are used most frequent today [8]. This trend initiated further advancement of anterior approaches and operative techniques via anterior approaches [7, 11, 14, 18, 21, 24]. There is an ongoing discussion about the "safe zones" and "dangerous zones" in acetabular surgery [25]. Due

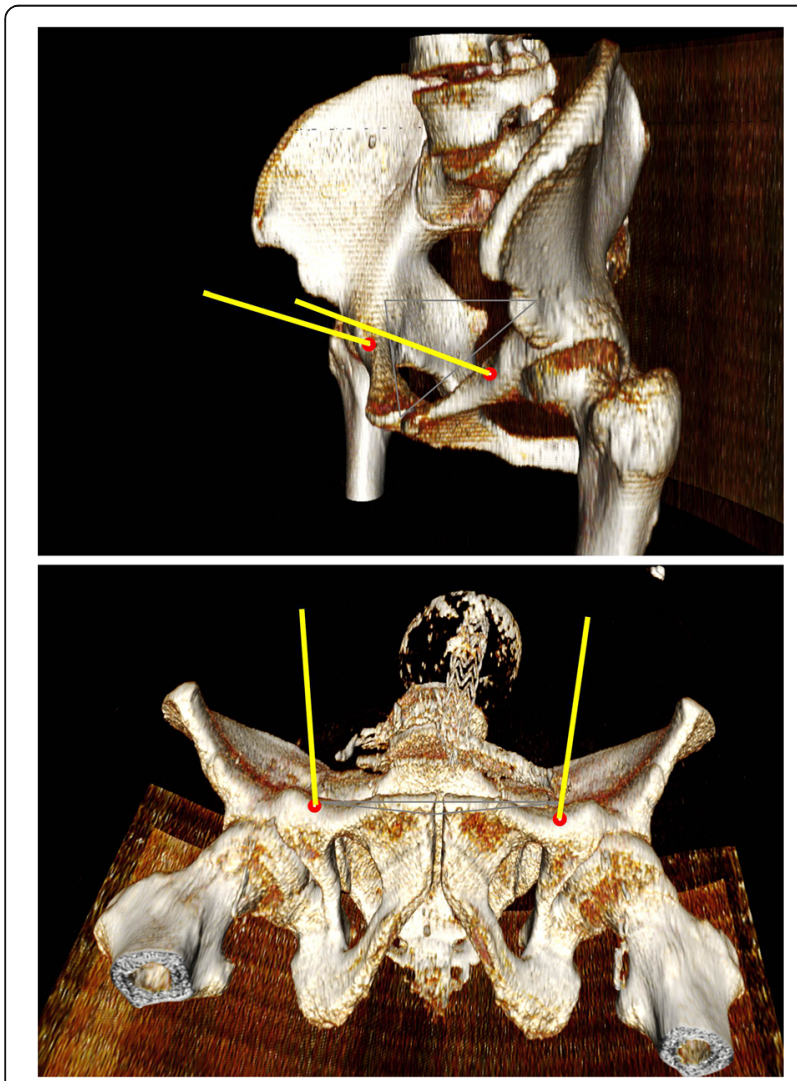

Fig. 4 3D-CT virtual reality images illustrating the angle of the drill of left and right screw by lines in relation to the PIP to the variance in pelvic anatomy, the safe zones are often relatively far away from the acetabulum, making it difficult to obtain adequate peri-acetabular stability. In 2011, Culemann et al. [5] proposed a modified quadrilateral screw inserted in the region of the Koehler's teardrop. This so-called infra-acetabular screw was intended to minimize the risk of intra-articular placement of the screw. The entry point for this modified screw was reported to be $1 \mathrm{~cm}$ caudal to the IPE and in the middle of the pubis ramus. When this infra-acetabular screw position was introduced, the anterior ilio-inguinal approach which allows direct access to the pubic ramus circumference was the most frequent anterior approach [19]. However, identification of the middle of the pubic ramus can be difficult via an intra-pelvic approach, which is the standard anterior approach today [8]. Therefore, the instructions to identify the ideal entry point determined by Culemann et al. [5] are not applicable via the intra-pelvic approach. We investigated the ideal screw position in CTbased 3D-models and determined the relation to anatomic landmarks which are intra-operatively palpable via an intra-pelvic approach. We indicate a reproducible guideline for the placement of an infra-acetabular screw via an intra-pelvic approach.

The major advantage of the intra-pelvic approach is a direct inspection of the quadrilateral surface which is often involved in geriatric fractures $[1-3,8,10,19,25]$. In cases of reduced bone quality, a simple fall can cause a fracture of the anteromedial acetabulum or the quadrilateral surface by load transmission through the major trochanter [4]. A lack of support of the quadrilateral surface has been identified as a risk factor for a secondary dislocation leading to a central subluxation of the femoral head $[6,11,20,24]$. In recent years, different concepts were introduced to increase medial support of the quadrilateral surface to prevent this complication $[3-5,7,10,11,18,21,24]$. 
Letournel was the first to describe the construct of a peri-acetabular frame to improve stability in acetabular fracture fixation [16]. They recommended a screw placement through the acetabular fossa. Culemann et al. [5] modified the position of this quadrilateral surface screw to the infra-acetabular corridor to minimize the risk of an intra-articular placement of the screw. The diameter of the drill hole for the infra-acetabular screw is $2.5 \mathrm{~mm}$. The standard $3.5-\mathrm{mm}$ fully threaded screw does not apply any inter-fragmentary compression force to the fracture and, therefore, only works as a distance screw. However, the main functions of this screw are a fixation of the anterior column to the posterior column and to prevent a dislocation of the quadrilateral surface $[5,18]$. Gras et al. [11] found in a biomechanical cadaveric study that an additional placement of an infra-acetabular screw significantly increases the stability of the fracture fixation compared to a standard plate fixation.

Recently, a large biomorphometric CT-based study identified a viable infra-acetabular corridor with a diameter over $5 \mathrm{~mm}$ in $93 \%$ of specimens [9]. This study measured the entry point in relation to the pubic symphysis. The pubic symphysis is well-accessible via an intra-pelvic approach. However, they found a large variance for this distance of 54-91 mm [9]. This variance is due to variation of the configuration of the pubic rim and makes this reference not useful for clinical practice. This study measured the angle of the screw to the anterior pubic plane. The APP is well-established in the determination of the pelvic tilt in hip arthroplasty [15]. It can be identified in a prone position and provides accurate and reproducible referencing plane in 3D-analyses. However, several studies have demonstrated an impairment in clinical reproducibility of the APP leading to inaccuracy of the implant position [22]. We intended to orientate the angle of the screw to a plane that is clearly visible for the surgeon via an intra-pelvic approach. Therefore, we chose the pelvic inlet plane as the reference plane which can be easily identified by the iliopubic brim and the symphysis. We could confirm the sexspecific differences in angulation of the screw reported by Gras et al. [9]. We found a mean length of $75 \mathrm{~mm}$ in female and $84 \mathrm{~mm}$ in male patients respectively. The screw length in our patient population was therefore somewhat shorter than that in other studies $[5,9]$.

This study has some limitations. The guideline for placement of the infa-acetabular screw is based on the identification of the IPE. This anatomic landmark is a large-area bony bump rather than a sharply marked spike. However, via an intra-pelvic approach, it is wellpalpable and its tip can easily be identified [25]. Another limitation to transfer this guideline into clinical practice is an insufficient reduction of the fracture. Incongruence of the infra-acetabular corridor can lead to narrowing of the designated screw canal or even to occlusion of the safe zone for screw placement. An intra-articular screw position may be the consequence. Therefore, an accurate radiographic review of the screw position is mandatory. Lastly, the limited number of cases reduces the generalizability of the guideline.

\section{Conclusion}

This study provides a comprehensive guideline to determine the ideal entry point for an infra-acetabular screw via an intra-pelvic approach. The entry point is located $10.2 \mathrm{~mm}$ caudal and $10.4 \mathrm{~mm}$ medial of the IPE. This reference is independent of age, gender, or physical dimensions. However, we found gender-dependent differences for the angulation and the length of the screw. Further prospective studies are needed to the proof effectiveness of this guideline in a clinical setting.

Abbreviations

$C T$ : Computer tomography; IPE: Ilio-pubic/ilio-pectineal eminence

\section{Acknowledgements}

The authors wish to thank the German Pelvic Multicenter Study Group (http://www.dgu-online.de) for their support in the conception of the study.

Funding

There was no third-party funding.

Availability of data and materials

Please contact the author for data requests.

Authors' contributions

FB designed the study, carried out the data interpretation, and drafted the manuscript. PS was involved in the interpretation of the data and preparation of the manuscript. DM carried out the data acquisition and correction work of the manuscript. MK was involved in the statistical elaboration and had significant impact on the finalization of the manuscript. AG conducted the literature research and contributed significantly to the preparation of the manuscript. MN contributed to the interpretation of the data and significantly improved the manuscript. MW participated in the design and coordination of the study and helped to draft the manuscript. All authors read and approved the final version of the manuscript.

\section{Ethics approval}

The Ethics Committee at the University of Regensburg approved the study in January 2018 (Institutional Review Board Number 17-705649-180). The study is registered at the Clinical Trial Registry University of Regensburg Z-2017-0930-1. All procedures performed in studies were in accordance with the 1964 Helsinki declaration.

\section{Consent for publication}

We have obtained consent to publish from all participants to report patient data.

\section{Competing interests}

The authors declare that they have no competing interest.

\section{Publisher's Note}

Springer Nature remains neutral with regard to jurisdictional claims in published maps and institutional affiliations.

\section{Author details}

'Department of Trauma Surgery, Regensburg University Medical Center, 93042 Regensburg, Germany. ${ }^{2}$ Clinic for Trauma Surgery, Orthopedics and Hand Surgery, Klinikum Wolfsburg, Wolfsburg, Germany. 
Received: 21 January 2018 Accepted: 25 March 2018 Published online: 10 April 2018

\section{References}

1. Bastian JD, Savic M, Cullmann JL, Zech WD, Djonov V, Keel MJ. Surgical exposures and options for instrumentation in acetabular fracture fixation: Pararectus approach versus the modified Stoppa. Injury. 2016;47(3):695-701. https://doi.org/10.1016/j.injury.2016.01.025.

2. Cole JD, Bolhofner BR. Acetabular fracture fixation via a modified Stoppa limited intrapelvic approach. Description of operative technique and preliminary treatment results. Clinical orthopaedics and related research. 1994;305:112-23

3. Collinge CA, Lebus GF. Techniques for reduction of the quadrilateral surface and dome impaction when using the anterior intrapelvic (modified Stoppa) approach. J Orthop Trauma. 2015;29(Suppl 2):S20-4. https://doi.org/10.1097/ BOT.0000000000000271.

4. Culemann U, Holstein JH, Kohler D, Tzioupis CC, Pizanis A, Tosounidis G, Burkhardt M, Pohlemann T. Different stabilisation techniques for typical acetabular fractures in the elderly_a biomechanical assessment. Injury. 2010:41(4):405-10. https://doi.org/10.1016/j.injury.2009.12.001.

5. Culemann U, Marintschev I, Gras F, Pohlemann T. Infra-acetabular corridor-technical tip for an additional screw placement to increase the fixation strength of acetabular fractures. J Trauma. 2011;70(1):244-6. https://doi.org/10.1097/TA.0b013e3181f45f91.

6. Ferguson TA, Patel R, Bhandari M, Matta JM. Fractures of the acetabulum in patients aged 60 years and older: an epidemiological and radiological study. The Journal of bone and joint surgery British volume. 2010;92(2):250-7. https://doi.org/10.1302/0301-620X.92B2.22488.

7. Gansslen A. Biomechanical principles for treatment of osteoporotic fractures of the pelvis. Unfallchirurg. 2010;113(4):272-80. https://doi.org/10.1007/ s00113-010-1763-2.

8. Gansslen A, Grechenig S, Nerlich M, Muller M, Grechenig W, Lindahl J. Standard approaches to the acetabulum part 3: intrapelvic approach. Acta Chir Orthop Traumatol Cechoslov. 2016;83(5):293-9.

9. Gras F, Gottschling H, Schroder M, Marintschev I, Reimers N, Burgkart R. Sex-specific differences of the infraacetabular corridor: a biomorphometric CT-based analysis on a database of 523 pelves. Clin Orthop Relat Res. 2015;473(1):361-9. https://doi.org/10.1007/s11999-014-3932-z.

10. Gras F, Marintschev I, Grossterlinden L, Rossmann M, Graul I, Hofmann GO, Rueger JM, Lehmann W. The anterior intrapelvic approach for acetabular fractures using approach-specific instruments and an anatomical-preshaped 3-dimensional suprapectineal plate. J Orthop Trauma. 2017:31(7):e210-6. https://doi.org/10.1097/BOT.0000000000000829.

11. Gras F, Marintschev I, Schwarz CE, Hofmann GO, Pohlemann T, Culemann U. Screw- versus plate-fixation strength of acetabular anterior column fractures: a biomechanical study. The journal of trauma and acute care surgery. 2012;72(6):1664-70. https://doi.org/10.1097/TA.0b013e3182463b45.

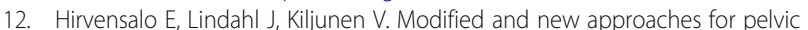
and acetabular surgery. Injury. 2007;38(4):431-41. https://doi.org/10.1016/ j.injury.2007.01.020.

13. Judet $\mathrm{R}$, Judet J, Lanzetta A, Letournel E. Fractures of the acetabulum. Classification and guiding rules for open reduction. Archivio di ortopedia. 1968:81(3):119-58.

14. Laflamme GY, Hebert-Davies J, Rouleau D, Benoit B, Leduc S. Internal fixation of osteopenic acetabular fractures involving the quadrilateral plate. Injury. 2011;42(10):1130-4. https://doi.org/10.1016/j.injury.2010.11.060.

15. Lass R, Kubista B, Olischar B, Frantal S, Windhager R, Giurea A. Total hip arthroplasty using imageless computer-assisted hip navigation: a prospective randomized study. J Arthroplast. 2014;29(4):786-91. https://doi.org/10.1016/j.arth.2013.08.020.

16. Letournel E. Surgical management of hip joint-acetabulum fractures. Langenbecks Archiv fur Chirurgie. 1966;316:422-37.

17. Letournel $E$. The treatment of acetabular fractures through the ilioinguinal approach. Clin Orthop Relat Res. 1993;292:62-76.

18. Marintschev I, Gras F, Schwarz CE, Pohlemann T, Hofmann GO, Culemann U. Biomechanical comparison of different acetabular plate systems and constructs - the role of an infra-acetabular screw placement and use of locking plates. Injury. 2012;43(4):470-4. https://doi.org/10.1016/j.injury. 2011.11.009
19. Ochs BG, Marintschev I, Hoyer H, Rolauffs B, Culemann U, Pohlemann T, Stuby FM. Changes in the treatment of acetabular fractures over 15 years: analysis of 1266 cases treated by the German Pelvic Multicentre Study Group (DAO/DGU). Injury. 2010;41(8):839-51. https://doi.org/10.1016/j.injury. 2010.04.010.

20. Pagenkopf E, Grose A, Partal G, Helfet DL. Acetabular fractures in the elderly: treatment recommendations. HSS journal : the musculoskeletal journal of Hospital for Special Surgery. 2006;2(2):161-71. https://doi.org/10.1007/ s11420-006-9010-7.

21. Schaffler A, Dobele S, Stuby F, Maucher M, Schroter S, Stockle U, Konig B. A new anatomical wing plate for osteoporotic acetabular fractures: biomechanical testing and first clinical experience. Zeitschrift fur Orthopadie und Unfallchirurgie. 2014;152(1):26-32. https://doi.org/10.1055/s-00331360351.

22. Sendtner E, Schuster T, Worner M, Kalteis T, Grifka J, Renkawitz T. Accuracy of acetabular cup placement in computer-assisted, minimally-invasive THR in a lateral decubitus position. Int Orthop. 2011;35(6):809-15. https://doi.org/ 10.1007/s00264-010-1042-4.

23. Tosounidis G, Culemann U, Bauer M, Holstein JH, Garcia P, Kurowski R, Pizanis A, Aghayev E, Pohlemann T (2011) Acetabular fractures in the elderly. Outcome of open reduction and internal fixation. Unfallchirurg 114 (8):655-662. https://doi.org/10.1007/s00113-011-2021-y.

24. White G, Kanakaris NK, Faour O, Valverde JA, Martin MA, Giannoudis PV. Quadrilateral plate fractures of the acetabulum: an update. Injury. 2013;44(2):159-67. https://doi.org/10.1016/j.injury.2012.10.010.

25. Zhang S, Su W, Luo Q, Leung F, Chen B. Measurement of the "safe zone" and the "dangerous zone" for the screw placement on the quadrilateral surface in the treatment of pelvic and acetabular fractures with Stoppa approach by computational 3D technology. Biomed Res Int. 2014;2014:386950. https://doi.org/10.1155/2014/386950.

\section{Submit your next manuscript to BioMed Central and we will help you at every step:}

- We accept pre-submission inquiries

- Our selector tool helps you to find the most relevant journal

- We provide round the clock customer support

- Convenient online submission

- Thorough peer review

- Inclusion in PubMed and all major indexing services

- Maximum visibility for your research

Submit your manuscript at www.biomedcentral.com/submit
) Biomed Central 